\title{
Language, Teaching and Attrition: A Study on Selected Teachers Who Left the Profession
}

\author{
Aminu Aliyu Wushishi (Corresponding author) \\ Center for interpretive and Qualitative Research (CIQR) \\ Duquesne University, Pittsburgh, Pennsylvania, United States \\ E-mail: amliyu@yahoo.com \\ Muhammed Baba \\ Dept. of Education Foundations, Niger State College of Education \\ Minna, Niger State, Nigeria
}

Doi:10.7575/aiac.alls.v.7n.1p.1

URL: http://dx.doi.org/10.7575/aiac.alls.v.7n.1p.1
Received: 18/08/2015

Accepted: 24/10/2015

\begin{abstract}
Nigeria is a country with over 520 different languages, the multitude nature of languages is making instructions so difficult in Schools, particularly in North-Central Nigeria where they have students with different language background attending the same school. The difficulty of smooth teaching in this kind of situation is leading to attrition among teachers. This study examines the situation of selected teachers in Niger State, Nigeria, who left the teaching profession as a result of difficulty in teaching their students, whom they said cannot efficiently understand the official language of instruction (English). The teachers highlighted their main reason of leaving the profession which is mainly associated with language problem among students, they added that, the massive failure of students in the final examination has a link with the student's inability to understand what the teachers are teaching because of their poor background in English language. The paper recommends the use of one major local language (Hausa) in teaching the students, this will make learning easy and students will efficiently comprehend instructions from their teachers, which may go a long way in reducing attrition.
\end{abstract}

Keywords: Language, Teaching, Attrition

\section{Introduction}

In Nigeria, there are concerns about the fact that teaching is a profession which is characterised by high rate of attrition (Bashar 2011). The problem of teacher retention is regularly headlined in the media and attracted series of researches among scholars in the country. The worry lies within the fact that many teachers in Nigeria who had invested time and effort into qualifying to teach had chosen to leave the profession. Growing concern about nationwide teacher shortage has focused considerable attention on education and teaching profession, several conditions account to this national crisis including increasing population of students' enrolment and teacher attrition (Garba 2012).

Throughout the decade, Nigerian schools required annual infusions of many new teachers to meet the demands of growing students' enrolments, expanded years of schooling, and teacher attrition issues (Bashar 2011). In a similar report, Adamu (2010) commented that school staffing problems are primarily due to excess demand resulting from a 'revolving door' where large numbers of teachers depart from their jobs for reasons other than retirement. While few numbers of Nigerian teachers remained stable in their positions, more teachers left the teaching profession than had entered. Thus, schools are losing more teachers than they are recruiting or retaining (Adamu 2010).

In Northern part of Nigeria, teacher attrition rate has rapidly raised within four years, in 2008 the rate was $13.9 \%$ but increased $20.1 \%$ in 2012, majority of the teachers moved to other profession due to some reasons like; improved condition of service in other profession, less stress, and working hours (Garba 2012).

In a report released by Niger State Secondary School Board, (2012) the rate of attrition from 2010-2012 was analysed. It has shown that as at 2010 the state has 12,280 teachers while in the same year a total of 1,338 which is about $10.9 \%$ exited out of the teaching profession. In 2011, the number increased to 1,702 amounting to $15.5 \%$. The number of teachers who quitted out of teaching profession in year the 2012 was reported to increase to 1,950 which is about $21.1 \%$. This shows consistent increase in teacher attrition in the state. Teachers are leaving the profession to other professions such as Immigration, Customs, Civil defence corps, Politics and other Civil service which has better payment and less stressful. One fundamental aspect of the report was that, from the year 2010-2012, the state has lost a total of 4,990 teachers as a result of attrition, which is about $47.5 \%$. Out of the three educational zones, Minna Educational Zone has the highest rate of attrition with $20.05 \%$, out of the $47.5 \%$, Bida educational zone with $15.3 \%$ and Kontagora zone with $12.2 \%$ within the period covered by the report. In addition, the rate of attrition was higher among male than female and within the early period of teaching career. 
Recent surveys conducted by Niger state secondary education board (2012) showed that, language subjects suffered in terms of teacher attrition. According to the report, the state has no enough qualified language teachers and 7 out of every 20 leave to other profession yearly. This number is significant compared to the number of schools in the state and high population of students in the schools.

In a study conducted by Ade (2010) on students of Language Dept. of a University in Lesotho found that almost twothird of those interviewed indicated that, they don't want to become teachers, and even if they become, they will leave the teaching profession and go into some different occupation within the next five years. This sign of extreme discouragement with the teaching profession is particularly common among language teachers who participated in the survey. This scenario of language teachers intending to leave the profession is common among schools in Nigeria particularly in the Northern part of Nigeria where the level of education is low compared to the Southern part of the country.

\section{Methodology}

To extract the views of teachers on why they left the profession, a qualitative method was used. Qualitative research is about understanding peoples' interpretation, their experience and meaning they attributes to certain phenomenon (Merriam: 2009). It has also been added by Creswell (2009) that, a qualitative method is a kind of method in research that is aimed at exploring or understanding the meaning individuals or groups ascribe to a social or human problem. In qualitative study the intention of the researcher is to listen to the voice of participants or observe them in their natural environments (Field \& Morse, 1992). There are different forms of qualitative research, but a phenomenological case study was selected in conducting this research with the aim of capturing the experience of the participants in details.

Five teachers who left teaching were purposively selected based on their experience in teaching and with vast idea on problem of language among the students they taught. The selection was done through snow balling. A teacher who left the profession was first identified, he then suggested other teachers who left as well. All the teachers selected are graduates in the different field of study.

In qualitative research, the researcher is the instrument unlike in quantitative research where a set of questions are itemised to solicit information. Interview is mainly used to collect data in qualitative research, to be supported by observation, and analysis of relevant documents. This research was also in line with the qualitative protocol. The researchers used interview to obtain their data from the participants. A tape recorder was used with the permission of the participants, and at the end of every interview session, before the next session of another interview the researchers transcribed the recorded interview verbatim so as make sure that no single vital information has escaped. The transcribed interview was visited and revisited severally with the aim of forming categories and the same process was adopted until the required themes emerged.

For the sake of confidentiality the participants were anonymously referred to as; Mr. A, B, C, D \& E

\section{Findings of the Study}

\subsection{Problem of English language among students}

One Important factor discovered by this study as causes for teacher attrition is language problem among students. Mr. D said,

There is a serious problem between us (teachers) and our students. Many of them do not understand English, as such you will spend the whole of time allocated for a period teaching and at the end the students may not understand what you are teaching. Whenever you asked the students questions regarding the treated lesson, you will realize that they don't understand what you taught them this has always been the problem with most of students in different schools of the State.

Mr. D explained further that, majority of the students in his class cannot write in English, and being a teacher he is so worried because if the students cannot effectively understand the lesson, then the aim is not achieved. He also pointed that, at times he has to use the local language in teaching the students, but the major problem is that, he can only speak one local language, while the students in the class came from different ethnic background, which he cannot speak all their local languages.

Mr. A highlighted on two of his friends who left teaching before him because of language problem among their students. He said,

John (an Igbo man) from the southern part of Nigeria came to this school as a Corper, and after his youth service he was retained to teach Economics, but after some months he had to leave because he is finding teaching difficult based on the fact that, he cannot combined teaching with the use of local language, because he cannot speak any of the local languages in the state. The same scenario also with Adewole who also left based on language. 
Mr. C commented that the issue of language problems has been there for long especially among village secondary schools, because he started his teaching career at a village secondary schools were more than $80 \%$ of the school population cannot speak English, and to even write in English has also been a problem. He said that

The issue of using English language as an official language is posing a great trait to our educational system especially the teaching profession. Many of our students cannot speak English and all the subjects in schools are taught in English, don't you think that there is a missing link?

Mr. C added that when he was teaching, the problem of language has been bothering his mind and is making it difficult for him to efficiently be delivering his lesson as expected.

Mr. E viewed language problem among students as a big problem which is made his teaching career so boring. He always find it difficult to cope with the students because of the language barrier, he felt that teaching combing two languages (Local and English language) is not always the best because the students are not writing their final examinations with the local language but with English language. So if they cannot effectively understand English then there is a problem at the end of their studies, hence they may likely fail their final examination. He concludes that, the issue of language to him is not making teaching interesting, and is among reasons why he left teaching. Mr. A shared his experience stating that,

Many of my students are having problem in English, and being the subject I taught, I find it difficult to cope with so many topics, in fact I have to repeat some topics so many times, that is why I hardly cover my syllabus before the end of the term.

He added that, the language problem is commonly with the junior classes, because majority of students at this level cannot speak and understand English, to even write in English is a problem. He concludes that, language problem can be enough to push teacher out of the teaching profession, hence every teachers' target is to impart knowledge to students.

Two of the participants Mrs. C \& D also mentioned language as a problem, but to them it has no much effects on the subjects they taught during their teaching career, $\mathrm{Mr}$. C was teaching Mathematics before he left the profession, while Mr. D was Agricultural scientist, but they both complained lightly on how their students were not coping with the subjects because of their inability in English Language. They decided to quit out of teaching profession because of the language problem among other reasons.

\subsection{Poor writing ability}

Another theme that emerged as reasons why the participant left the teaching was poor writing ability of their students. Apart from the poor outspoken language, many students lack the writing skills. Mr. C, commented that, whenever he administered a test to his students, marking their scripts is usually a big problem because, he cannot read some scripts he added that, I don't understands what is wrong with our students their writing ability is so poor that you can hardly understand what they are saying. This is in line with the views of Mr. D who asserted that, beside the language problem among students that led him to leave the profession, another reason was the poor writing ability of the students. He stated that; it is annoying after teaching and you give assignment to the students and the students cannot be able to write perfectly, particularly students at the senior secondary school level.

Mr. A and E shared the same opinion that, it is not all their students have have the poor writing ability, some of them can write as expected but majority have the poor writing ability and to them, the problem is making teaching uninteresting, that was why they left to another job. Although, Mr. E further explained that, the poor writing ability was not his primary reason for his leaving the profession, but it was among other reasons for his attrition.

Mr. B gave different opinion stating that, during his teaching career, there was no much issue with the writing ability among the student he taught. He asserted that, majority of them can efficiently write and their writing ability was perfect. He added that, his attrition was as a result of language problem among the students.

\section{Discussion}

\subsection{Language problem among students}

Language problem was the major factor of attrition among the participants who left the teaching job. All the participants complained that, they are facing difficulties in their teaching because many of their students are having problem with the official language (English). Nigeria is a country with different languages, there are more than 250 different languages (Bawa \& Salahu 2012). In Niger state alone, where this study was conducted, there are over 20 different languages. Bawa \& Salahu, (2012) identified the existence of over 25 different languages in the state.

The interviewed teachers indicated that, the problem was serious during their teaching career and even made them with some of their colleagues to drop teaching to other jobs. One of the teachers complained that, it is disturbing to teach for the whole period while the students couldn't comprehend, then it will be as equal as learning has not taken place. In support of this, Patricia (1998) stated that, learning occurs when individuals are able to make meaning from interrelated pieces of information which can only be done with the use of language. Language plays an important role in human life. Chater \& Christiansen (2011) viewed language as the primary vehicle through which much other cultural information is transmitted either in school or at home, and hence may have produced a crucial catalytic role in the development of 
other aspects of human culture and society. In a document produced by Queensland government of Australia (2005), stated that, $14 \%$ of their students have special needs in communicating, many of these related to their underlying language capacity.

The researchers were made to understand that, the problem of language among secondary school students in the study area, emanated from the nature of primary schools in the states, which serve as the feeders to secondary schools. Most of the primary school teachers use local language in teaching the pupils, while the law says English should be the language of instruction. Although this problem is not peculiar to the study area alone. In Pakistan Coleman (2010), reported that, teachers in public schools tend to use local language in teaching their students, neglecting the use of English. The author further attributes the attitudes of the teachers to their lack of confidence in their competence or their poor ability to speak English.

To ascertain the issue Language problem among students, the researchers visited some selected secondary schools to observe how instructions using the official language was going. It can been observed from the visit that, effective instruction is becoming difficult for teachers in their teaching process and it seems the students are finding the instruction a bit difficult because of their poor background on English language which was said to be the official language of Nigeria.

Another discovery on why the interviewed participants left the teaching profession was the issue of poor writing ability among their students. Although one of the five participants admitted that, during his teaching career he had no problem with the writing ability among his students. But the remaining four participants indicated that their students' writing ability was poor and discouraging in the profession.

\section{Conclusion}

This study provides understanding on problem of language among students, which is becoming difficult for teachers in terms of effective teaching. This could be as a result of multiple mother tongue among students in the study area and the use of foreign language (English) as a medium of instruction. It will be better if government will enact a policy of adopting the major local language (Hausa) as a medium of instruction, as done in Malaysia and many other South East Asian countries where local language is used as official language. This will help in making teachers' instruction easy and facilitate learning among students. Before concluding this part, it is important to note that, there were no much available studies on teacher attrition in relation to language problem, most studies on causes of teacher attrition focuses on low salary, poor working environment, Schools leadership style and so on.

\section{References}

A report on "Teacher Survey Analysis" (2012) Niger State Secondary Education Board.

Adamu A. (2010) A Techniques on improving Staff Morale in Public Secondary Schools in Bauchi State. Unpublished Master thesis, Bayero University Kano, Nigeria.

Ade M.L (2010) Students intention to teaching profession. A survey for ministry of Education Lesotho.2010

Australian Department of Education (2012) Promotion and transfer procedure for school teachers retrieved on $25^{\text {th }}$ Sept. 2013 www.ed.gov.au

Bashar M. (2011). Reforming the Teacher: An imperative for attaining the Nigerian Educational aims. International Journal of Teacher Education and Teaching, 4(1), 1-9.

Bawa M.M \& Salahu M.L (2012). A study on Nigeria people and culture. Star publishers. Minna.

Chater, N., \& Christiansen, M. H.(2011). A solution to the logical problem of language evolution: language as an adaptation to the human brain. The Oxford Handbook of Language Evolution, Oxford University Press, Oxford, 626639

Coleman H. (2010). Teaching and learning in Pakistan: The role of learning in education. The United Kingdom's international organization for cultural relations and educational opportunities. British Council.

Creswell, J.W (2009) Research Design Qualitative, Quantitative and Mixed Methods Approaches. Sage publishers: London.

Field, P.A., \& Morse, J.M. (1992). Nursing research. The application of qualitative approaches. London: Chapman \& Hall.

Garba N.A. (2012). An outlook on Educational system in Northern Nigeria. Journal of Teacher Education,3(2), 5-11.

Merriam S.B. (2009). Qualitative research A guide to design and implementation: Revised and expanded from Qualitative and case study application in education $2^{\text {nd }}$ edition. San Francisco: Jossey- Bas publication. 